\section{Response to Jaber and Bonneys' comments}

As acknowledged in Jaber and Bonney's (JB) response, ${ }^{1}$ the two major issues are: (1) Is the $\mathrm{JBM}^{2}$ model correct? (2) Do $\mathrm{JBM}$ and $\mathrm{ZLM}^{3}$ produce different results?

On the first issue, $\mathrm{JB}^{1}$ do not refute our claim that the original $\mathrm{JBM}^{2}$ is mathematically incorrect, but justify it by pointing out that an 'approximation' disclaimer was explicitly stated in their paper. We therefore would like to retract our claim that the original JBM is incorrect, and would merely state that our model $^{3}$ removes the 'approximation' in JBM.

On the second issue, $\mathrm{JB}^{1}$ do not refute our claim that the ZLM exact expression is hardly more complicated than JBM's ${ }^{2}$ approximate expression, but they present more than one page of mathematical derivations to reach the conclusion that 'Arguably, in most practical cases, (the ZLM and
JBM expressions differ by) a negligible value.' We do not see the need to disagree with this conclusion.

Hefei University of Technology, Anhui,

People's Republic of China

City University of Hong Kong, Hong Kong

Y-W Zhou

H-S Lau

\section{References}

1 Jaber MY and Bonney M (2001). Comments on Zhou and Lau's reply. J Opl Res Soc 52: 591-592.

2 Jaber MY and Bonney M (1996). Optimal lot sizing under learning considerations: the bounded learning cases. Appl Math Model 20: $750-755$.

3 Zhou YW and Lau H-S (1998). Optimal production lot-sizing model considering the bounded learning case and shortages backordered. J Opl Res Soc 49: 1206-1211. 